\title{
Photogrammetry of Chin as a Requisite Preoperative Evaluation of Cosmetic Rhinoplasty
}

\section{Javad Rahmati', Hamidreza Fathi' ${ }^{2}$, Nigar Sultanova3 ${ }^{3}$ Mahammad M. Davudov', Hosein Ali Danesh4*}

${ }^{1}$ Razi and Imam Khomeini Hospital, Tehran University of Medical Sciences, Tehran, Iran

${ }^{2}$ Tehran University of Medical Sciences, Tehran, Iran

${ }^{3}$ Azerbaijan Medical University, Baku, Azerbaijan

${ }^{4}$ Zahedan University of Medical Sciences, Zahedan, Iran

Email: ${ }^{\star}$ Iran.mahammad_davud@mail.ru

How to cite this paper: Rahmati, J., Fathi, H., Sultanova, N., Davudov, M.M. and Danesh, H.A. (2020) Photogrammetry of Chin as a Requisite Preoperative Evaluation of Cosmetic Rhinoplasty. International Journal of Otolaryngology and Head \& Neck Surgery, 9, 86-91.

https://doi.org/10.4236/ijohns.2020.92012

Received: October 25, 2019

Accepted: March 6, 2020

Published: March 9, 2020

Copyright $\odot 2020$ by author(s) and Scientific Research Publishing Inc. This work is licensed under the Creative Commons Attribution International License (CC BY 4.0).

http://creativecommons.org/licenses/by/4.0/

\section{Open Access}

\begin{abstract}
Introduction: The aim of this study is evaluation of chin deformities and their role in rhinoplasty cosmetic surgery outcomes via photogrammetry of chin. Materials and Methods: The study is a cross sectional one. All photos of rhinoplasty surgery candidates of three hospitals (Amir Aalam, Imam Khomeini and Razi of Tehran) which were taken in standard lateral position via SLR cameras were assessed through Adobe Photoshop CS, in order to determine four different aesthetic measurements. Except for excluded photos due to our excluding criteria or technical problems, all photographs were evaluated carefully. Results: 144 photos of patients were enrolled. The oldness of patients ranges between below 20 up to above; 65.99 patients were female (68.8\%) and 45 were male. 73 patients (50.7\%) had an abnormal silver condition. Moreover 9 patients (6.3\%) with abnormal nasomental, 124 patients with abnormal status of Gonzalez-Ulloa (93.8\%), 63 patients (43.8\%) with unusual status of Ricketts' E line/upper and 49 patients (34\%) with abnormal Ricketts' E line/lower status can be demonstrated. Discussion: Performing a photogrammetric study for candidates of cosmetic rhinoplasty also a chin examination as a mandatory preoperative assessment seems to be essential. Due to the lack of studies in this field, more studies are necessary.
\end{abstract}

\section{Keywords}

Photogrammetry, Chin, Rhinoplasty

\section{Introduction}

Due to the following facts that: firstly the shape and size of chin has a crucial role 
in the final aesthetic outcome of a rhinoplasty; the operation of the genioplasty may be beneficial prior to or even cost-benefit at the same time with rhinoplasty, consequently the evaluation of chin may be essentially prior to rhinoplasty surgery. Chin assessment may be a cost benefit and informative measure for the preoperative aesthetic assessment of the face also a good case selection of patients undergoing rhinoplasty [1]-[8].

On the other hand, the prevalence of patients requires chin surgery simultaneously or before rhinoplasty may be more than our primitive projections. Particularly among Iranian patients undergoing rhinoplasty, it is not well established and recognized. Therefore, the study was done to assess the prevalence and type of chin disproportions and deformities and a probable need for genioplasty in Iranian patients who undergone rhinoplasty. In light of all the above mentioned facts, the importance and role of genioplasty, it will be not a surprising trend if an increasing number of men and women below 55 years want genioplasty procedure and this practice steadily increases [1] [9] [10] [11]. As a result, in some patients along with rhinoplasty also the chin may need sort of corrections [12] [13] [14] [15]. In recent years chin photogrammetry is utilized as a precise measure in order to evaluate its deformities as in the study that Jahangir Ahmad et al. have made [16]. The value and accuracy of the photogrammetric study of human face is comparable with the cephalometric study [3]. Finally, chin photogrammetry can be a cost-benefit and reliable method of evaluation in preoperative assessment of every single case of cosmetic rhinoplasty.

\section{Materials and Methods}

This cross-sectional study was conducted on all rhinoplasty surgery candidates who were admitted in three main plastic surgery hospitals of Tehran including Amir Aalam, Imam Khomeini and Razi hospitals.

The inclusive criteria contained all photos of rhinoplasty surgery candidates of three hospitals (Amir Aalam, Imam Khomeini and Razi of Tehran) during a one year period in 2019. Written consent was taken from all participants according to Tehran University of Medical Sciences University rules. Excluding criteria of the study were: poor quality or bad position of photos; history of previous jaw surgery; history of any jaw fracture or severe facial trauma, any underlying diseases or skin diseases, previous facial plastic surgery, facial deformities, the participant own decision for exclusion and any other error in photography and data recording. All participants were permitted to leave the experiment on their own decision any time by raising a simple request. The patient followed up till their surgery recovery.

Imaging technique:

Classically different methods have been used to determine the size and shape and aesthetic problems of chin. Four well-known methods: Silver medial and zero-median; Gonzalez-ulloa; Ricketts' E line upper and lower and nasomental angle were utilized to measure aesthetic indices of the photos. Images were taken from seated volunteers by an operator. The photos were taken in standard lateral 
position via SLR cameras assessed through Adobe Photoshop CS finally in order to determine four different aesthetic measurements. Moreover, age; sex; and anthropometric parameters which were related to nasal assessments were recorded and evaluated at the same time. Data gathered using questionnaire and analyzed using SPSS version 18 software.

\section{Results}

Photos of 144 patients were assessed. The age classification range included: 25 patients under 20 years old (17.4\%); 71 patients of 20 - 30 years old (49.3\%); 34 patients of 30 - 40 years old (23.6\%) and 14 patients of 40 - 50 years old (9.6\%). Of which 99 belongs to women (68.8\%) and 45 belongs to men. According to measurements: 73 (50.7\%) abnormal silver; 9 (6.3\%) abnormal nasomental line; 124 abnormal status of gonzalez-ulloa (93.8\%); 63 (43.8\%) abnormal status of Ricketts' E line/upper and 49 (34\%) abnormal Ricketts' E line /lower status were found in the patients photos.

The number of chin photographic disorders in women and men are as shown in Table 1. It is noticeable that, the only significant difference between the abovementioned photogrammetric parameters of two sexes owe to the abnormality of Ricketts' E line/lower which was higher in males than females ( $48.9 \%$ versus $27.3 \%)$.

To sum up, the ubiquity of people with chin abnormalities in more than 3 photogrammetric parameters were about 3 times higher in men than women (33.3\% vs. $9.1 \%)$.

The results of chin photogrammetric assessment do not show any meaningful differences in abnormalities among different age groups. There was no significant difference between the prevalence of photos with more than 3 chin abnormality measurements compared to the photos with less than 3 chin abnormality measurements among different age groups, in total (Table 1).

\section{Discussion}

Mentoplasty or genioplasty or chin plastic surgery is a technique for improving the shape and size of the chin with microgenia or macrogenia. This surgery is typically done to fill the lower face and preserve nasal symmetry. Moreover prior to any rhinoplasty operation, it is essential to perform photogrammetry for all patients. Sometimes X-ray imaging of chin and face or even a CT scan may be obligatory [4] [5] [6] [9]. Decision making may become more complicated when diversity among aesthetic values and genetic diversities have to be considered. For instance Hussein Rad et al. revealed that all head and face anthropometric indices in native women of Mashhad were different from males and Gandahan et al. pointed that Persian youths were different in fascial aesthetic parameters from Caucasian youths. The width and length of facial aesthetic parameters in young women of Mashhad were significantly bigger than young Caucasian women [10] [17] [18] [19]. 
Table 1. Frequency of chin abnormalities.

\begin{tabular}{cccc}
\hline & & Frequency & Percent \\
\hline \multirow{2}{*}{ (silver) } & \pm 3 (normal) & 71 & $49 / 3$ \\
& abnormal & 73 & $50 / 7$ \\
Gonzalez-ulloa & \pm 2 (normal) & 20 & $13 / 9$ \\
& abnormal & 124 & $86 / 1$ \\
Nasomental & normal & 135 & $93 / 8$ \\
& abnormal & 9 & $6 / 3$ \\
Ricketts' E line/upper & normal & 81 & $56 / 3$ \\
& abnormal & 63 & $43 / 8$ \\
Ricketts' E line/lower & normal & 95 & $66 / 0$ \\
& abnormal & 49 & $34 / 0$ \\
\hline
\end{tabular}

Mohammad Reza Farah Vash concluded that the majority of facial anthropometric criteria were different in Iranian women and men, and also had a significant difference with the Caucasian race [10]. Shiva Alavi in an anthropometric study of Isfahan youth, found that due to the significant difference between anthropometric sizes in Iranian youth themselves, consequently there is a need for highly precise evaluation foe each patient independently and there will be no similar recommendation for all of the patients. Moreover, may international standards cannot be used as a reference for the treatment of all Iranian patients [18].

Danahey and colleagues believe that there should be a fit between the nose and the chin and recommend that patients undergoing rhinoplasty must have counseling for genioplasty at the same time [19]. Mayer has introduced photogrammetry and cephalometry as a method for analyzing soft tissue and skeleton of the face to recognize asymmetry and [20] and Johnstown in complementary mandibular lesions correction [21]. Bertossi et al. in a study on candidates of rhinoplasty and genioplasty stated that: in addition to evaluation for rhinoplasty there must be an assessment for microgenia or macrogenia to see if they need genioplasty or not [22].

Jahangir Ahmed recommended to surgeons who perform rhinoplasty that all patients should be screened for lower face evaluation before rhinoplasty, and if necessary, perform a genioplasty before or at the same time as rhinoplasty [16].

Tamdo Dian showed that accurate photogrammetric analysis in patients with rhinoplasty candidates to choose appropriate treatment for chin plays an important role in facial beauty and genioplasty in patients may affect the need for nose modification [23]. A study examines the complications associated with genioplasty at the same time with rhinoplasty and found that its complications cannot be increased if the anatomy is accurately diagnosed and the patient is properly selected [11].

In our study, 73 patients (50.7\%) had an abnormal silver condition, 9 patients 
(6.3\%) had abnormal nasomental, 124 patients with abnormal status of Gozalez-Ulloa (93.8\%), 63 patients (43.8\%) had Unusual status of Ricketts' E line /upper and 49 patients (34\%) have an abnormal Ricketts' E line/lower status, accordingly performing a photogrammetric study for candidates of rhinoplasty and careful chin examination prior to operation may be cost-benefit, necessary and new method on order to improve the final outcome of surgery. Due to the lack of studies in this field seems more studies on bigger study samples must be done on this matter.

\section{Conflicts of Interest}

The authors declare no conflicts of interest regarding the publication of this paper.

\section{References}

[1] Rohrich, R.J., et al. (2014) Dallas Rhinoplasty: Nasal Surgery by the Masters. CRC Press, London.

[2] Lee, E.I. (2013) Aesthetic Alteration of the Chin. In: Seminars in Plastic Surgery, Thieme Medical Publishers, Stuttgart. https://doi.org/10.1055/s-0033-1357113

[3] Omrani, A., et al. (2012) Comparison of Anthropometry and Digital Photography Techniques in Facial Proportion Analysis. 453-462.

[4] Rustemeyer, J. and Martin, A. (2013) Soft Tissue Response in Orthognathic Surgery Patients Treated by Bimaxillary Osteotomy: Cephalometry Compared with 2-D Photogrammetry. Oral and Maxillofacial Surgery, 17, 33-41.

https://doi.org/10.1007/s10006-012-0330-0

[5] Ghoddousi, H., et al. (2007) Comparison of Three Methods of Facial Measurement. International Journal of Oral and Maxillofacial Surgery, 36, 250-258. https://doi.org/10.1016/j.ijom.2006.10.001

[6] Weinberg, S.M., et al. (2006) Anthropometric Precision and Accuracy of Digital Three-Dimensional Photogrammetry: Comparing the Genex and 3dMD Imaging Systems with One Another and with Direct Anthropometry. Journal of Craniofacial Surgery, 17, 477-483. https://doi.org/10.1097/00001665-200605000-00015

[7] Jain, S., Anand, C. and Ghosh, S. (2004) Photometric Facial Analysis: A Baseline Study. Journal of the Anatomical Society of India, 53, 11-13.

[8] Zijlker, T.D., Vuyk, H. and Adamson, P.A. (1992) Rhinoplasty: Preoperative Photographic Analysis. Clinical Otolaryngology and Allied Sciences, 17, 361-369. https://doi.org/10.1111/j.1365-2273.1992.tb01014.x

[9] Nechala, P., Mahoney, J. and Farkas, L.G. (1999) Digital Two-Dimensional Photogrammetry: A Comparison of Three Techniques of Obtaining Digital Photographs. Plastic and Reconstructive Surgery, 103, 1819-1825. https://doi.org/10.1097/00006534-199906000-00002

[10] Pezeshki Rad, H., Jahanbin, A. and Modabber, M. (2007) An Investigation on Facial and Cranial Anthropometric Measurements among 20-35 Year Old Individuals in the City of Mashhad. Journal of Mashhad Dental School, 31, 261-268.

[11] White, J.B. and Dufresne, C.R. (2011) Management and Avoidance of Complications in Chin Augmentation. Aesthetic Surgery Journal, 31, 634-642.

https://doi.org/10.1177/1090820X11415516 
[12] Jobe, R., Iverson, R. and Vistnes, L. (1973) Bone Deformation Beneath Alloplastic Implants. Plastic and Reconstructive Surgery, 51, 169-175. https://doi.org/10.1097/00006534-197302000-00012

[13] Guyuron, B., Michelow, B.J. and Willis, L. (1995) Practical Classification of Chin Deformities. Aesthetic Plastic Surgery, 19, 257-264. https://doi.org/10.1007/BF00451101

[14] Kridel, R. (1987) Adjunctive Measures to Rhinoplasty. Otolaryngologic Clinics of North America, 20, 895-912.

[15] Gibson, F.B. and Calhoun, K.H. (1992) Chin Position in Profile Analysis: Comparison of Techniques and Introduction of the Lower Facial Triangle. Archives of Otolaryngology-Head \& Neck Surgery, 118, 273-276. https://doi.org/10.1001/archotol.1992.01880030057013

[16] Ahmed, J., Patil, S. and Jayaraj, S. (2010) Assessment of the Chin in Patients Undergoing Rhinoplasty: What Proportion May Benefit from Chin Augmentation? Otolaryngology-Head and Neck Surgery, 142, 164-168. https://doi.org/10.1016/j.otohns.2009.10.041

[17] MR, F. and Gh, K. (2011) Anthropometric Analysis of Faces and Heads of 18 to 30-Year Old Persians and Its Comparison with Caucasian Ethnic Group. Tehran University Medical Journal TUMS Publications, 69, 359-365.

[18] Alavi, S. and Safari, A. (2003) An Investigation on Facial and Cranial Anthropometric Parameters among Isfahan Young Adults. Journal of Dental Medicine, 16, 19-28.

[19] Danahey, D.G., et al. (2001) Importance of Chin Evaluation and Treatment to Optimizing Neck Rejuvenation Surgery. Facial Plastic Surgery, 17, 91-98. https://doi.org/10.1055/s-2001-17757

[20] Arroyo, H.H., et al. (2016) Clinical Evaluation for Chin Augmentation: Literature Review and Algorithm Proposal. Brazilian Journal of Otorhinolaryngology, 82, 596-601. https://doi.org/10.1016/j.bjorl.2015.09.009

[21] Rustemeyer, J. and Gregersen, J. (2012) Quality of Life in Orthognathic Surgery Patients: Post-Surgical Improvements in Aesthetics and Self-Confidence. Journal of Cranio-Maxillofacial Surgery, 40, 400-404. https://doi.org/10.1016/j.jcms.2011.07.009

[22] Bertossi, D., et al. (2013) Combined Rhinoplasty and Genioplasty: Long-Term Follow-Up. JAMA Facial Plastic Surgery, 15, 192-197. https://doi.org/10.1001/jamafacial.2013.759

[23] Sykes, J.M. and Suárez, G.A. (2016) Chin Advancement, Augmentation, and Reduction as Adjuncts to Rhinoplasty. Clinics in Plastic Surgery, 43, 295-306. https://doi.org/10.1016/j.cps.2015.09.021 